\title{
The Relationship of Behavioral Factors with Investment Performance of Individual Investors in the Nepali Stock Market
}

\author{
Kripa Kunwar \\ School of Business, Pokhara University, Nepal
}

Article History: Submitted 15 February 2021; Reviewed 21 April 2021; Accepted 02 May 2021

Corresponding Author: Kripa Kunwar, Email: kripakunwar@gmail.com DOI: https://doi.org/10.3126/paj.v4i0.37016

Copyright 2021 ( ) Author/s and Centre for Research and Innovation.

This work is licensed under a Creative Commons Attribution 4.0 International (CC BY 4.0) License.
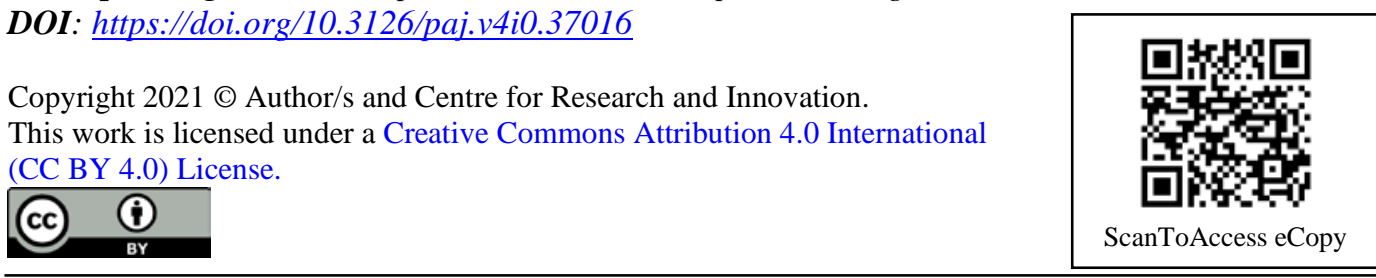

\begin{abstract}
In recent years, the market anomalies and irrational behavior of investors have influenced the stock market worldwide. The impact of investor behavior on the stock market is more prominent in small and less efficient capital markets. The study is based on the questionnaire survey of 203 investors from Kathmandu and Pokhara. The study uses Exploratory Factor Analysis (EFA) to explore the underlying dimensions of investor behavior employing Principal Component Analysis and Varimax rotation. The suitability of the data for the factor analysis has been examined using KMO and Barlett's Test of Sphericity. The EFA extracted four factors of investor behavioral dimensions categorized as: heuristics, prospects, market factors and herding effect. The factor scores obtained from the EFA was used to examine the correlation of these behavioral factors with investment performance. The results reveal that behavioral biases like heuristics, prospects, market factor and herding effect are present among individual investors in Nepal. Among the factors, the investment performance of investors is found to be influenced by heuristics and market factors. The heuristic behaviors are found to have the highest and positive influence on the investment performance. Finally, the results depict that following the herd behavior in the market and prospects does not result in the improved investor performance. The findings are helpful to understand the role of investor behavior in the stock market and formulation of appropriate policies that limit the possibility of behavioral biases affecting the stock market adversely.
\end{abstract}

KEYWORDS: Behavioral finance, herding effect, heuristics, market factors, prospects

\section{INTRODUCTION}

The stock market is a backbone of the country's economy. It is one of the most dynamic sectors of the economy, which is considered as a barometer of financial health of country's economy. The development of stock market in a country is essential for the 
growth of the economy (Tachiwou, 2010). Changes in the stock market has a great influence in the financial system and economy of the country. Therefore, it is important to understand the way of functioning of the stock market. In contrast to the concepts of traditional finance, behavioral finance posits that investor psychology and emotions are the prime factors that affect the stock market movement. The essences of traditional finance theories have four foundation blocks. These are: investors are rational, markets are efficient, investors should design their portfolio according to the rules of mean variance portfolio, and expected returns are a function of risk and risk alone (Statman, 2008). The Efficient Market Hypothesis (EMH) explains that investors behave rationally in the financial market after processing all the available information to estimate the price of financial assets and maximize expected utility accurately. Investors make the investment decision after analyzing all possible alternatives because it is a process in which investors have to choose one of the courses of action from among the alternatives under uncertainty. Similarly, the Expected Utility Theory (EUT) states that investors are rational and their decision is based on the balance between utility and risk after judging the available alternative.

However, behavioral economists argue that traditional financial theories are not enough and that numerous psychological processes drive individuals to the investment decision making (Slovic, 1972). According to Kumar and Goyal (2015), behavioral finance is the new concept in the finance, which has evolved since 1980 by incorporating the psychological and behavioral aspects in economics and the financial decision making. Behavioral finance which considers the human behavior in finance is a new dimension in finance. Moreover, behavioral finance counters the traditional finance theory and suggests the multiple behavioral biases that impact individual investment decisions (Budhiraja et al., 2018). Further, it explains why the investors behave in a particular manner while investing in the financial market. Behavioral finance helps to understand how the investor in the financial market makes a decision and how financial markets would be affected by these decisions. The study of behavioral finance makes clear about the importance of cognitive psychology in finance. The financial decision making of human being is affected by psychological biases instead of being rational all the time. For researchers of behavioral finance, the Asian financial market is meaningful because Asians suffers more from cognitive biases than people from other culture (Kim \& Nofsinger, 2008). Through the understanding of behavioral finance, the investors can make better investment decision as well as investors can avoid the repetition of the expensive mistake in future by understanding their biases and errors of decision to which we are all prone (Chaudhary, 2013). Moreover, the study of behavioral finance may assist for well-functioning of market.

Investors are the real player of stock market. Generally, two kinds of investors participate in the stock market; these are institutional investor and individual investor. Institutional investors seem rational and make the smart investment decision due to their expertise and knowledge. On the other hand, unlike institutional investors, individual investors are likely to be less informed more biased and common noise traders in the financial market (Kyle, 1985; Black, 1986). When it comes to investment, people make the decisions based on their emotions, feeling and sentiments, which ultimately influence investment decision (Statman et al. 2008). Hence, the investment decision of individual investors is influenced by psychological biases. It shows that investment behavior of the small investors is influenced by various factors that are the ultimate determinants of the market performance. The investor's decisions in the stock market play a significant role in shaping the market trend, which then affects the economy (Shabgou \& Mousavi, 
2016). Thus, this study is focused on behavior of individual investors in the stock market in the context of the Nepali stock market.

The history of securities market in Nepal began with the commencement of shares by Biratnagar Jute Mills Ltd. and Nepal Bank Ltd. in 1937. The first issuance of Government Bond in 1964 and the establishment of Securities Exchange Center Limited in 1976 were the important development relating to capital markets (NEPSE). Nepal Government under a program initiated to reform capital markets converted securities exchange center into Nepal Stock Exchange in 1993 (NEPSE). The time series data of index data shows that NEPSE seems very volatile in nature (Koirala \& Bajracharya, 2002). The stock market anomalies, which include the extreme rise and fall in the price of stock market in Nepal is the greatest problem that can be observed. Investors do not behave as they are expected to behave in the market. On the other hand, there is lack of trust, proper guidance and regulations in the stock market among the brokers and investors. Prevalence of unethical acts of promoters, share brokers, high volatility in the market, poor investment knowledge of the small investors and high degree of uncertainty and risk exists. NEPSE should avoid both speculative gains and dramatic losses within a small time frame to protect the market from crashes. The stock market of Nepal seems beneficial to the investors who can overlook the rules of game. Hence, although the study of behavioral biases is crucial, such studies are scanty in Nepali context (Koirala \& Bajracharya, 2004). Prior studies have focused only on some dimensions of investor behavior only and most studies have focused on the herding effect. Hence, there is a need to undertake a study by incorporating comprehensive dimensions of behavior of the investors. This study makes an effort to develop a sound understanding of behavior of individual investors in Nepal Stock Exchange by incorporating a comprehensive set of investor behaviors in making the investment decision. Based on the behavioral finance literature, this study attempts to investigate the issue: Do behavioral factors like heuristic, prospect, herding behavior and market variable affect the stock investment performance of individual investors in Nepal? Hence, the purpose of the study is to explore understanding of the behavioral biases of individual investors in Nepal Stock Exchange and to empirically examine the influence of behavioral factors on the investment performance.

\section{BEHAVIORAL ASPECTS AND BIASES PRESENT IN INVESTMENT DECISION}

Behavioral finance studies the impact of psychology on the financial decision making and financial markets (Shefrin, 1988). Different studies which focus on the human behavior makes it clear that human emotions, intentions, intuitions and habits play a large role in all financial decisions (Budhiraja, et. al., 2018). Behavioral finance focuses on the investors psychology and its impact on the financial decision making. This is an area of finance, which argues with the assumption of rationality present in the traditional finance theories and provides the counter-evidence that the real investors are influenced by their psychological biases. In addition, these psychological biases lead to such a behavior that may be the reason of suboptimal decisions. Such decisions can be a cause of nosinesss in the market and are known as market anomalies. Market anomalies and volatility can have the poor effect on the individual financial health as well as of the overall economy. Such anomalies in the stock market needs to be prevented (Kapoor \& Prosad, 2017). Behavioral finance integrates the theories like prospect theory, heuristic theory, herding and market factors, which are explained below. 


\section{Prospect Theory}

Prospect theory was developed by Kahneman and Tversky (1979) that shows how people decide between the alternatives that involve risk and uncertainty. It focuses on the subjective decision making, which is influenced by the individual value system. It is an alternative theory of choice, which explained that people make a decision based on the potential value of gains and losses rather than the final outcomes, as well as setting reference points and making decisions accordingly. People valued gains and losses differently in which value is calculated from a reference point. Moreover, people consider possible gains and possible losses differently and give a preference to possible gains over possible losses even when the outcome from both options is the same (Budhiraja, et al., 2018). It shows that people think in terms of expected utility relative to a reference point (e.g current wealth) rather than absolute outcomes. So decisions are related to the probability of an event that could be the theme of major biases and heuristics (Kahneman \& Tversky, 1979). Regret aversion, loss aversion and mental accounting are some states of mind that affect an individual's decision making processes (Waweru et al., 2008).

\section{Heuristics}

Heuristic is considered a strategy for making decisions, which disregards the part of information in the process of making decisions quickly, frugally and accurately than more complex methods (Gigerenzer \& Gaissmaier, 2011). Heuristics turn out to be tied to biases, but the content-free laws of logic and probability became recognized with the principles of sound thinking (Tversky \& Kahneman, 1974). According to Gigerenzer and Gaissmaier (2011), heurisics are defined as efficient cognitive processes, conscious and unconscious that avoid the part of the information. In addition, heuristics are considered an effort reduction process by evaluating only some cues, decreasing the effort of retrieving cue values, simplifying the weighting of cues, incorporating few information and assessing fewer alternatives (Shah \& Oppenheimer, 2008).

Heuristics are rules of thumb, which make decision making easier especially in complex and uncertain situation (Tversky \& Kahneman, 1974). It decreases the difficulty of assessing probabilities and predicting values to simple judgments. They further explain that irrational people used heuristics because they fail to judge the perfect probability. Heuristics could be useful if a decision should be made under limited time (Waweru et al, 2008) and limited information (Kahneman \& Tversky, 1974). A better understanding of different types of heuristics biases like representativeness, availability, anchoring, overconfidence and gambler's fallacy may improve judgments and decisions under uncertainty.

\section{Market Factors}

Market factors also have a great impact on the decision making process of investors in the stock market. Waweru et al. (2008) found that price changes, market information, past trends of stocks, customer preference, over reaction to price change and fundamentals of underlying stocks are the market factors that influence the decision making of investors. Changes in market information, fundamentals of underlying stocks and stock price could be the basis of over and under reaction to the price change and these changes are empirically proved to have a high influence on the decision making behavior of investors. According to DeBondt and Thaler (1995), the investors show different reactions on the market factors that determine different trading strategies by the investors, which influence their investment decision. Moreover, DeBondt and Thaler (1995) argue that the financial markets can be influenced by the investor's behaviors in 
accordance to behavioral finance. A number of market forces influence the investor's decisions and performance. Barber and Odean (2000) state that the investors are influenced by events in the stock market, which hold their attention, even when they cannot assess the opportunity of good future investment performance as an outcome of such events.

\section{Herding}

Herding is the behavior of investors in the stock market in which a large number of people act in the same way at the same time. It can be defined as the investor's tendency toward following other investor's behavior in the financial market (Ranjbar et al., 2014). In addition, herding is the behavior of investor's where they tend to act according to other's actions rather than own private information to act. It exists because in the financial market, the rational investor starts behaving irrationally by mimicking the decisions of others. Generally, the individual investor shows herd behavior by following the decisions of a large group (Kumar \& Goyal, 2015). Waweru et al. (2008) state that herding can lead stock trading to and build the momentum for stock trading.

Zahera and Bansal (2018) state that the behavioral finance incorporates herding as the collective irrational behavior of investors where investors have the trend to follow others in the stock market. Herding happens in both the rising and falling market condition and herding behavior exists under both the general and specified markets condition, including bull and bear markets, and high-low trading volume states. The rational investors of the stock market always make their own decision based on their own information and does not follow the mass. In contrast, the investors imitate the group when they do not have sufficient knowledge and information to make decision.

\section{METHODOLOGY}

\section{Measurement and Instrumentation}

The behavioral finance constructs and variables used in the study is based on Waweru et al. (2008). They identify four constructs representing major behavioral biases present in the stock market investors, viz., heuristics, prospects, herding and market factors. The behavioral variables used in the study comprise of sub-constructs of heuristic (5), herding (5), prospects (3), and market factors (6) as shown in Table I. The variables have been operationalized using 26 items presented in Annex I using a 6-point Likert scale.

Table 1

Behavioral Factors Influencing the Investment Decision Making

\begin{tabular}{llc}
\hline Construct & Behavioral Variables & Cronbach's Alpha \\
\hline Heuristics & Representativeness & 0.81 \\
& Overconfidence & \\
& Anchoring & \\
& Gambler's fallacy & \\
& Availability & 0.87 \\
\hline Prospect & Loss aversion & \\
& Regret aversion & 0.83 \\
& Mental accounting & \\
\hline Market & Price change & \\
& Market information & \\
& Past trends of stocks & \\
& Fundamentals of underlying stocks & \\
\hline
\end{tabular}

Prithvi Academic Journal, Volume 4, May 2021 [pp. 66-83] 


\begin{tabular}{lll}
\hline & Customer preference \\
& Over- reaction to price changes & \\
\hline Herding Effect & Trading decisions of other investors & 0.85 \\
& Choice of stock to trade of other \\
& investors \\
& Volume of stock to trade of other \\
& investors \\
& Speed of herding \\
& Impact of other investor's decisions \\
\hline
\end{tabular}

Source: Waweru et al., 2008

A structured questionnaire was developed to collect information on investor behavior and investment performance. The questionnaire was divided into four parts: personal information, investment profile, behavioral factors influencing investment decisions and investment performance. In order to collect the investors' opinions on behavioral dimensions of their investment decision, 6-point Likert scale was used for asking the respondents' opinions and attitudes to evaluate the degree of their agreement about the behavioral factors influencing investment decisions and investment performance.

The scale used to measure the abstract concept of the investor behavior used in the study is a multi-dimensional scale with four sub-dimensions (herding, prospect, heuristic and market factor) comprising a total of 26 scale Likert scale items (See Annex I) to measure the 19 behavioral variables shown in Table 1 . The scale items are indicators of behavioral biases recognized by the behavioral finance theories that the individual investors exhibit while making their investment decision and comprises of 6 anchor points ( 1 = Extremely disagree, 2 = Highly disagree, 3 = Somewhat disagree, $4=$ Somewhat agree, 5 = Highly agree, $6=$ Extremely agree). The scale is balanced scale and has no neutral point in order to force responses. Additionally, investor performance is measured as a unidimensional concept with 3 indicator items.

The items used for operationalization of the study variables has been presented in Annex I. The reliability of the measurement scale was ascertained employing Cronbach's alpha. The reliability of constructs used in questionnaire survey is accessed via internal consistency reliability measure Cronbach's Alpha. The overall item's alpha value is 0.84 . This value indicates that each individual item in a scale is well correlated with remaining items. It shows that internal consistency is high on the data. The study employs validated scale developed by Waweru et al. (2008) as an instrument to measure the investor behavior.

\section{Data Collection}

Data were collected from the individual stock market investors in Nepal through an investor survey. The study areas selected purposively were Kathmandu and Pokhara. The main reason behind in selecting these cities are a considerable presence of majority of investors and availability of brokerage houses. A visit to brokerage houses present in the cities was undertaken to collect the data. The investors visiting the brokerage office were requested to participate in the survey. A total of 300 questionnaires were distributed and 203 completed questionnaires collected during the three months' survey period with the response rate of 68 percent.

A proper care was taken during the study to ensure that a breach of research ethics was not undertaken. The prior acceptance was taken from the respondents before approaching them with the survey questionnaire. The questionnaire was accompanied by a covering letter that explained the aim of the study and identified the researcher, asked 
for the questionnaire to be completed, explained the nature and importance of the study, and assured the participants that their responses would be treated in confidence. To ensure confidentiality, the name of the respondents was not asked and information was kept confidential. It was a voluntary participation of the respondents after their consent.

\section{Data Analysis Techniques}

As the study seeks to explore the underlying dimensionality of the investor behavior in the stock market in Nepal, it employs the exploratory factor analysis (EFA) to validate and summarize the underlying dimensions of the investor behavior. The KMO and Barlett's test have been used to ascertain the suitability of the survey data for the factor analysis. EFA has been undertaken employing the principal component analysis and orthogonal rotation as the objective of factor analysis in the study that is the data summarization for use in the subsequent analysis. After obtaining the factor scores, the correlation analysis was conducted to identify an association of investor performance with the factor scores representing the heuristics, prospects, market and herding effect as independent variables.

\section{RESULTS AND DISCUSSION \\ Profile of Sample Investors}

The demographic characteristics of the individual investors of NEPSE have been categorized as gender, age, level of education, nature of employment and monthly income. The information collected through the questionnaire regarding the demographic variables was recorded and analysed in percentiles using SPSS. The summary of demographic characteristics of respondents has been presented in the Table 2. The result shows that the majority of the sample respondents are male, aged 31-40 years, having the master's level education or above and self-employed job.

Table 2

Demographic Profile of the Survey Respondents

\begin{tabular}{llcc}
\hline Profile & Group & Frequency & Percentage \\
\hline Gender & Male & 172 & 85 \\
Age & Female & 31 & 15 \\
& less than 30 & 39 & 19 \\
& $31-40$ & 83 & 41 \\
Level of Education & $41-50$ & 51 & 25 \\
& More than 50 years & 30 & 15 \\
& Under SLC & 8 & 4 \\
& Intermediate (+2) & 28 & 14 \\
Nature of & Bachelor & 50 & 24 \\
Employment & Master and above & 117 & 58 \\
& & 82 & 40 \\
& Self-employment & 68 & 34 \\
& Formal employment & 8 & 4 \\
& Housewife & 33 & 16 \\
& Both formal and self- & 10 & 5 \\
employment & 2 & 1 \\
Monthly Income & Retired & 89 & 44 \\
& Others & 91 & 45 \\
\hline
\end{tabular}

Prithvi Academic Journal, Volume 4, May 2021 [pp. 66-83] 


\begin{tabular}{lrr}
\hline $100,001-150,000$ & 9 & 4 \\
Above 150,000 & 14 & 7 \\
\hline Total (N) & $\mathbf{2 0 3}$ & \\
\hline
\end{tabular}

Table 2 reveals that the majority of the respondents included in the study are male. 85 percent of the respondents are male whereas female comprises only 15 percent out of the total respondents. It indicates a lower proportion of female respondents as compared to male. Similarly, it reveals that the majority of the respondents fall in the age group of 31-40 with the percentage of 41 . It gives a picture that the middle age respondents are involved in their study. Comparatively, a participation of very young respondents and old age respondents is low. The sample comprises of majority of the educated investors as shown by 58 percent of the respondents' fall under the category of master's degree education and above. Finally, the majority of the sample investors are self-employed.

Similarly, Table 3 provides the description of the sample by their investment profile. The results show that the majority of the sample investors have not taken any training on investment, they have a low investment experience, have invested marginally in the stock market and consider themselves long term investors.

Table 3

Investment Profile of Respondents

\begin{tabular}{llcc}
\hline \multicolumn{1}{c}{ Profile } & \multicolumn{1}{c}{ Group } & Frequency & Percentage \\
\hline Attended training & Yes & 78 & 38 \\
& No & 125 & 62 \\
Investment & Less than 1 year & 28 & 14 \\
Experience & 1-3 year & 69 & 34 \\
& 3-5 year & 36 & 18 \\
& 5-10 year & 46 & 22 \\
& Over10 year & 24 & 12 \\
Investment & Below 10,00,000 & 71 & 35 \\
Amount (In NRs.) & 10,00,001- & 43 & 21 \\
& 20,00,000 & & \\
& 20,00,001- & 35 & 17 \\
& 30,00,000 & 54 & 27 \\
& Above 30,00,000 & 22 & 11 \\
Type of Investor & Short term & 107 & 53 \\
& Long term & 74 & 36 \\
& Cannot say & $\mathbf{2 0 3}$ &
\end{tabular}

Table 3 depicts that 62 percent of respondents have not attended any training and only 38 percent have attended trainings. In the same manner, the table also summarizes the result of investment experience of the respondents. The investment experience of the respondents is categorized into five groups. Most of the sample respondents (34\%) have 1-3 years of investment experience. Likewise, 22 percent respondents fall under 5-10 years' class. The result indicates that the respondents have a variety of investment experience. Accordingly, 35 percent respondents have below Rs. 10,00,000 investments whereas 27 percent has above Rs. 30,00,000 investments in the share market. Likewise, 53 percent respondents accepted that they are long term investors and only 11 percent said that they are short term investors. However, 36 percent said that they cannot say exactly what kind of investors they are. 


\section{Description of Investor Behavior}

Table 4 reveals the status of investor's behavior as perceived by individual investors who participate in the trading in NEPSE. The respondents were asked to give their likeliness on six point Likert scale to confirm whether they agree on the investment behavior as indicated by the scale. It is observed that the investment behavior of individual investors is influenced by behavioral biases and psychological factors. The overall mean score of 3.94 indicates the moderate influence of behavioral factors on investment behavior of individual investors. Among four behavioral variables like herd, prospect, market and heuristic, it can be said that market is the major influencing variable with the highest mean score of 4.45. Likewise, prospect is the second major influencing variable and herd is the least influencing among four with moderate effect on the investment behavior of the individual investor in NEPSE.

Table 4

Descriptive Analysis of Investors' Behavior

\begin{tabular}{ccccc}
\hline $\begin{array}{c}\text { Particular } \\
\text { s }\end{array}$ & Minimum & Maximum & Mean score & Significant \\
\hline Herd & 1.00 & 6.00 & 3.32 & .88250 \\
Prospect & 2.00 & 6.00 & 4.06 & .90555 \\
Market & 1.83 & 6.00 & 4.45 & .88499 \\
Heuristic & 2.14 & 6.00 & 3.91 & .77093 \\
\hline \multicolumn{5}{c}{ Overall Mean } \\
\hline
\end{tabular}

N=203; Scales: 1=Extremely Disagree, 6 = Extremely Agree

\section{Analysis of Investor Behavior Dimensions and Its Influence in Investment Performance}

In this section, the results of factor analysis and correlation analysis have been presented and the findings of the results have been discussed. Exploratory Factor Analysis was used for data summarization, identify the factors representing underlying dimensions of investor behavior and calculate the factor scores. The factor scores calculated from the factor analysis was used in the subsequent correlation analysis to analyze the effect of investor behavior on the investment performance.

Initially, EFA is employed in order to identify the underlying dimensionality of the latent construct and to extract factors, which represent the sub-dimensions of investor behavior using the survey data of stock market investors in Nepal. The factor analysis was conducted iteratively removing the variable not supported by the model on the basis of cross-loadings and communalities. The final EFA model is run using 13 selected items representing investor behavior. The summarization of the large number of indicators into few for facilitating interpretation and further analysis was necessary. Relationships among sets of many interrelated variables collected from the questionnaire survey are examined and have been represented in terms of a few underlying factors. Hence, the exploratory factor analysis is used in the study to reduce a large number of variables perceived to influence the investor behavior into a few factors and to assess the preliminary validity of the scale used in the study as well as to calculate factor scores to be used in the subsequent analysis. 
Table 5

Assessing Suitability of Data for Factor Analysis

\begin{tabular}{lcc}
\hline \multicolumn{3}{c}{ KMO and Bartlett's Test } \\
\hline Kaiser-Meyer-Olkin Measure of Sampling Adequacy. & 0.78 \\
Bartlett's Test of Sphericity & Approx. Chi-Square & 1239 \\
& Df & 10 \\
& Sig. & 0.000 \\
\hline
\end{tabular}

The applicability of the factor analysis on the survey data is determined using KMO and Bartlett's test. The results of the tests are exhibited in Table 5. The Bartlett's test of Sphericity is a test statistic used to examine the null hypothesis that the variables are uncorrelated in the population. In the study survey data, the null hypothesis is not accepted at $1 \%$ level of significance which indicates the presence of significant correlations making the dataset useful for factor analysis. The Kaiser-Meyer-Olkin (KMO) measure of sampling adequacy is an index used to examine the appropriateness of factor analysis. High values ( 0.5 to 1 ) indicate that the factor analysis is appropriate. The KMO index for the dataset is 0.78 , thus, the factor analysis is considered an appropriate technique for analyzing the interdependence among variables in the dataset.

Table 6

Factor Extraction and Variance Explained

\begin{tabular}{ccccccc}
\hline \multirow{2}{*}{ Components } & \multicolumn{3}{c}{} & \multicolumn{3}{c}{ Rotation Sums of Squared } \\
Loadings
\end{tabular}

Once, it has been determined that the factor analysis is suitable for analyzing the data, the appropriate method must be selected. In the study, the factor analysis is done using the principal component analysis and the Varimax rotation method. The method of extraction begins by finding a linear combination of variables (a component) that accounts for as much variation in the original variables as possible. It then finds another component that accounts for as much of the remaining variation as possible and is uncorrelated with the previous component, continuing in this way until there are as many components as original variables. Usually, a few components or factors will account for most of the variation, and these components can be used to replace the original variables. This method is most often used to reduce the number of variables in the data file.

The total column of Table 6 gives the Eigenvalue, or amount of variance in the original variables accounted for by each component. The \% of variance column gives the 
ratio, expressed as a percentage, of the variance accounted for by each component to the total variance in all of the variables. The cumulative \% column gives the percentage of variance accounted for by the first $n$ components. For example, the cumulative percentage for the second component is the sum of the percentage of variance for the first and second components.

A number of components or factors is determined using Eigenvalues and scree plot. An Eigenvalue represents the amount of variance associated with the factor. Only factors with Eigenvalues greater than one are extracted. For the initial solution, there are as many components as variables, and in a correlations analysis, the sum of the Eigenvalues equals the number of components. In Table 6, only the first four components have Eigenvalues greater than one. Hence, the factor analysis has extracted four factors from the extracted solution. The scree plot also reveals presence of four factors of investment behavior.

The second section of the Table 6 shows the extracted components. They explain $64.96 \%$ of the variability in the original 13 variables, so the complexity of the data set can be considerably reduced by using these components, with less loss of information. The rotation maintains the cumulative percentage of variation explained by the extracted components, but that variation is now spread more evenly over the components. The large changes in the individual totals suggest that the rotated component matrix will be easier to interpret than the unrotated matrix. Hence, the factor analysis has reduced the 13 initial variables into four factors.

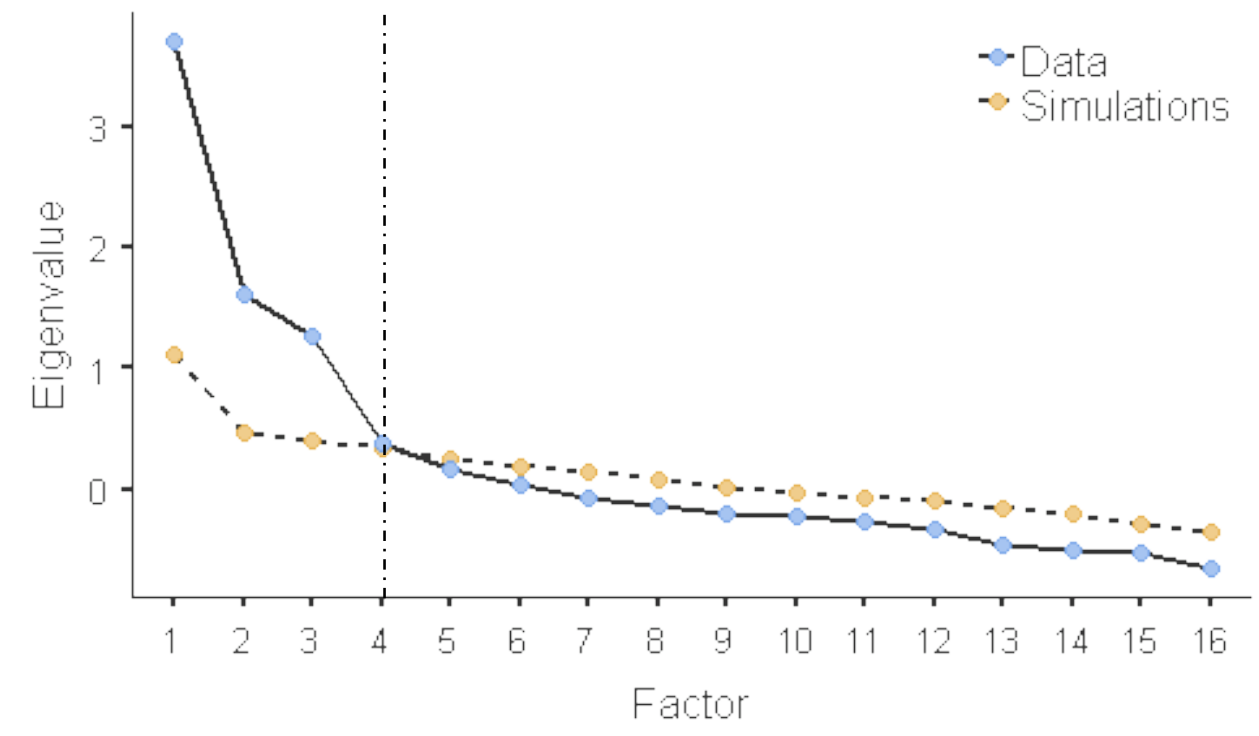

Fig. 1. Factors Extracted Using Scree Plot

Table 7

Rotated Component Matrix and Factor Loadings

\begin{tabular}{|c|c|c|c|c|c|}
\hline & \multicolumn{4}{|c|}{ Factor } & \multirow[b]{2}{*}{ Uniqueness } \\
\hline & 1 & 2 & 3 & 4 & \\
\hline HB1 & & & 0.713 & & 0.485 \\
\hline HB2 & & & 0.657 & & 0.554 \\
\hline
\end{tabular}

Prithvi Academic Journal, Volume 4, May 2021 [pp. 66-83] 
Table 7

Rotated Component Matrix and Factor Loadings

\begin{tabular}{|c|c|c|c|c|c|}
\hline & \multicolumn{4}{|c|}{ Factor } & \multirow[b]{2}{*}{ Uniqueness } \\
\hline & 1 & 2 & 3 & 4 & \\
\hline HB3 & & & 0.642 & & 0.569 \\
\hline HB4 & & & 0.666 & & 0.544 \\
\hline PRP1 & & & & 0.334 & 0.798 \\
\hline PRP2 & & & & 0.852 & 0.282 \\
\hline PRP3 & & & & 0.434 & 0.636 \\
\hline MF1 & 0.726 & & & & 0.435 \\
\hline MF2 & 0.921 & & & & 0.216 \\
\hline MF3 & 0.750 & & & & 0.426 \\
\hline MF4 & 0.560 & & & & 0.478 \\
\hline HEU1 & & 0.350 & & & 0.711 \\
\hline HEU4 & 0.358 & 0.301 & & & 0.598 \\
\hline
\end{tabular}

Note. 'Principal Component Analysis' was used in combination with a 'Varimax' rotation

An important output from the factor analysis is the factor matrix, also called as component matrix shown in Table 7. The factor matrix contains the coefficients used to express the standardized variables in terms of factors. These coefficients, the factor loadings, represent the correlations between the factors and the variables. A coefficient with a large absolute value indicates that the factor and the variable are closely related. The coefficients of the factor matrix are used to interpret the factors. Although the initial or unrotated factor matrix indicates the relationship between the factors and their individual variables, it seldom results in factors that can be interpreted, because the factors are correlated with many variables. Therefore, thorough rotation, the factor matrix is transformed into a simpler one that is easier to interpret. The rotated component matrix helps to determine what the components represent.

The EFA also provided a factor solution of four factors with 13 items as shown in Table 7. Only factor loadings greater than 0.3 have been shown as loadings with lower values are considered insignificant. Uniqueness is the variance that is unique to the variable and not shared with other variables. It is equal to one minus communality (i.e. the variance shared with other variables). Consistent with the prior theoretical literature on the behavioral finance, the factors are labelled as the market factor, heuristic, herding and prospects respectively. The mean scores and description of the extracted factors and their indicators are presented in Table 8. 


\section{Table 8}

Description of Extracted Factors and Indicators

\begin{tabular}{|c|c|c|c|c|}
\hline SN & $\begin{array}{c}\text { Latent } \\
\text { Construct }\end{array}$ & Items & $\begin{array}{l}\text { Mean } \\
\text { Scores }\end{array}$ & Statement \\
\hline 1 & Herding & HB1 & 2.84 & $\begin{array}{l}\text { I usually react quickly to the changes of } \\
\text { other investors' decision and follow their } \\
\text { reactions to the stock market. }\end{array}$ \\
\hline 2 & & HB2 & 3.11 & $\begin{array}{l}\text { I often imitate decision of others when } \\
\text { making own investment decision. }\end{array}$ \\
\hline 3 & & HB3 & 3.06 & $\begin{array}{l}\text { Bearish trend in the stock market forces me } \\
\text { to follow group behavior regarding } \\
\text { investment. }\end{array}$ \\
\hline 4 & & HB4 & 3.45 & $\begin{array}{l}\text { Bullish trend in the stock market forces me } \\
\text { to follow group behavior regarding } \\
\text { investment. }\end{array}$ \\
\hline 5 & Prospect & PRP1 & 4.31 & $\begin{array}{l}\text { I avoid selling shares that have decreased } \\
\text { in value and readily sell shares that have } \\
\text { increased in value. }\end{array}$ \\
\hline 6 & & PRP2 & 4.17 & $\begin{array}{l}\text { I feel more sorrow about holding losers too } \\
\text { long than about selling winning stocks too } \\
\text { soon. }\end{array}$ \\
\hline 7 & & PRP3 & 4.30 & $\begin{array}{l}\text { I tend to treat each element of my } \\
\text { investment portfolio separately. }\end{array}$ \\
\hline 8 & Market & MF1 & 4.72 & $\begin{array}{l}\text { I consider carefully the price changes of } \\
\text { stocks that I intend to invest in. }\end{array}$ \\
\hline 9 & & MF2 & 5.01 & $\begin{array}{l}\text { Market information is important for my } \\
\text { stock investment. }\end{array}$ \\
\hline 10 & & MF3 & 4.69 & $\begin{array}{l}\text { I put the past trends of stocks under my } \\
\text { consideration for my investment. }\end{array}$ \\
\hline 11 & & MF4 & 4.53 & $\begin{array}{l}\text { I study the market fundamentals of the } \\
\text { underlying stock before making investment } \\
\text { decisions. }\end{array}$ \\
\hline 12 & Heuristic & HEU1 & 3.90 & $\begin{array}{l}\text { I am normally able to anticipate the end of } \\
\text { good or poor market returns at NEPSE. }\end{array}$ \\
\hline 13 & & HEU4 & 4.23 & $\begin{array}{l}\text { I rely on my previous experiences in the } \\
\text { market for my next investment. }\end{array}$ \\
\hline 14 & $\begin{array}{c}\text { Investor } \\
\text { Performance }\end{array}$ & IP1 & 3.43 & $\begin{array}{l}\text { The return rate of your recent stock } \\
\text { investment meets your expectation. }\end{array}$ \\
\hline 15 & & IP2 & 3.67 & $\begin{array}{l}\text { My rate of return is equal to or higher than } \\
\text { the average return rate of the market. }\end{array}$ \\
\hline 16 & & IP3 & 3.76 & $\begin{array}{l}\text { You feel satisfied with your investment } \\
\text { decisions in the last year. }\end{array}$ \\
\hline
\end{tabular}

The following Table 9 displays correlations of investor behavior subdimensions; herding behavior (HB), heuristic (HEU), prospect (PRP), and market factor (MF) with investment performance (IP). The mean scores and standard deviation of the sub-constructs have also been shown. 
Table 9

Correlation Matrix of Investment Behavior's Sub-Scales with Financial Performance

\begin{tabular}{lccccccc}
\hline & Mean & SD & Performance & Herd & Prospect & $\begin{array}{c}\text { Market } \\
\text { Factor }\end{array}$ & $\begin{array}{c}\text { Heurist } \\
\text { ics }\end{array}$ \\
\hline Performance & 3.62 & 1.22 & 1 & & & & \\
Herding & 3.12 & 1.14 & 0.028 & 1 & & & \\
Prospect & 4.26 & 1.08 & 0.093 & 0.075 & 1 & & \\
Market & 4.74 & 1.00 & $0.228^{* *}$ & $0.147^{*}$ & $0.463^{* * *}$ & 1 & \\
Factor & & & & & & \\
Heuristics & 4.86 & 1.02 & $0.425^{* * *}$ & -0.019 & $0.335^{* * *}$ & $0.486^{* * *}$ & 1 \\
\hline
\end{tabular}

*, **, and *** means the coefficient is significant at 10\%, 5\%, and $1 \%$ level of significance respectively.

The result indicates that the behavioral biases are present to some extent among investors in Nepal as all mean scores are higher than three. The highest score is for the market factor, which reveals that behavior like over-reaction, extrapolation of past trends and focus on popular stocks is prevalent among the investors. Similarly, the investors are also found to exhibit loss aversion, regret aversion and mental accounting behavior as posited by the prospects theory. Heuristics behavior like overconfidence, anchoring and gambler's fallacy are also present in stock market investors in Nepal. The investor behavior like buying and selling following other investors' trade, stock trade volume and following the market trend is also prevalent in the Nepali stock market. However, the results show that although herding behavior is found to be present, it is less prominent than other behavioral biases. The mean value of perceived investment performance reveals that investment in the Nepali stock market offers satisfactory return to the investors.

The result of correlation analysis reveals that the behavioral factors of individual investors in the Nepali stock market is related with their investment performance. Behavioral biases related to market factor and heuristics are found to be positively correlated with investment performance. The study results depict that investors in the Nepali stock market show herding, prospects, heuristic and market factor behavior as explained in the behavioral finance literature. Among the investor behavior in the Nepali context, heuristics is the largest behavioral bias present followed by the market factor. Consistent to the findings of Waweru et al. (2008) and Shah and Oppenheimer (2008) heuristics biases seem to result in the efficient cognitive processes, conscious and unconscious that make the investors in Nepal choose selective information through behavior like represenatition, overconfidence, anchoring and gamble's fallacy, which impacts performance positively. Similarly, the study findings offer empirical support for results of prior studies (Barber \& Odean, 2000; and Kumar \& Goyal, 2015) in the role of market factor based investment biases that investors follow like price changes, market information, past trends of stocks, customer preference, over reaction to price change and fundamentals of underlying stocks are the market factors that influence the decision making of investors.

As per the item-wise mean scores, the mental accounting behavior, which is subdimension of prospects has been identified as the most important behavioral bias, which results in the investment losses. Similarly, the regret aversion behavior is another important sub-dimension of prospects bias that affects the investment performance negatively. The investor behavior based on market factors like extrapolation of past trends, market information seeking, and reaction to price changes are found to result in better investor performance. Additionally, as found by Budhiraja et al. (2008) following 
investment decision of other investors is also found to have positive relationship in the investment performance. A quick reaction to market trend is also found to be beneficial for performance. Finally, the gambler's fallacy and anchoring are found to have no relation with investment performance. Hence, the results support the findings of prior empirical studies in the investor behavior and indicate that an understanding of behavioral finance biases is important for the investors investing in the Nepali stock market.

\section{CONCLUSION}

The paper attempted to develop understanding of various factors affecting the investor behavior and their association with the investment performance in the Nepali stock market. Consistent with the findings from the similar stock markets, behavioral biases like heuristics, prospects, market factor and herding effect are present among the individual investors in Nepal. Biases related to prospects and market factors like loss and regret aversion behavior, following market trend, and reacting to price changes have a moderate influence on the investor performance. The heuristic behaviors are found to the highest and positively related with the investment performance. The heuristic behavior like overconfidence in their investment ability and exhibiting gamblers fallacy tendency are important dimensions of the investor behavior. The investment performance of investors is related with heuristics and market factors. Following the herd behavior in the market and prospects, it does not result in the improved investor performance. The implications of the findings for the stock market investors are the study conclusion that the understanding of investor behavior is crucial for attaining investment success. For policymakers, the findings are helpful in understanding the role of investor behavior in the stock market and formulation of appropriate policies that limit the possibility of behavioral biases, affecting the stock market adversely.

The study offers an understanding of relationship of behavioral factors on the investment decision and performance of individuals at the Nepal Stock Exchange. The study is based on the approaches of behavioral finance, which is different from prior studies in Nepal. It is one of the few studies on factors influencing the investor decisions, incorporating all broad domains of behavioral finance. The study tries to incorporate a full set of behavioral factors to assess their effect on the investors while most prior studies only consider the impacts on some limited dimensions of behavioral factors. The study included a few limitations such as a certain selection of the sample from selected cities, which may induct some bias due to a particular geographical and economic advantage of the place. It is necessary to have further researches to confirm the findings of this research with the larger sample size and more diversity of the sample investors. Hence, future research directions of particular interest would be to attempt to generalize the factors explored in the study. It would be better to consider even institutional investors and make a comparison of behavior between the institutional and individual investors.

\section{REFERENCES}

Adhikari, P. (2010). Investment behaviour of Nepalese investors. PYC Nepal Journal of Management, 3(1), 34-57.

Barber, B.M., \& Odean, T. (2000). Trading is hazardous to your wealth: The common stock investment performance of individual investors. Journal of Finance, 55(2), 773-806.

Black, F. (1986). Noise. The Journal of Finance, 41(3), 528-543. 
Budhiraja, K., Raman, T., \& Bhardwaj, G. N. (2018). Impact of behavioral finance in investment decision making. International Journal of Civil Engineering and Technology, 9(6), 1151-1157.

Chaudhary, A. K. (2013). Impact of behavioral finance in investment decision and strategies - A fresh approach. International Journal of Management Research and Business strategy, 2(2), 86-102.

De Bondt, W. F., \& Thaler, R. H. (1995). Financial decision-making in markets and firms: A behavioral perspective. Handbooks in operations research and management science, 9, 385-410.

Festinger, L., Riecken, H.W., \& Schachter, S. (1956). When Prophecy Fails: A Social and Psychological Study of a Modern Group that Predicted the Destruction of the World (1st ed.). University of Minnesota Press.

Gigerenzer, G., \& Gaissmaier, W. (2011). Heuristic decision making. Annual Review of Psychology, 62(1), 451-482.

Kapoor, S., \& Prosad, J. M. (2017). Behavioural finance: A review. Procedia Computer Science, 122(1), 50-54.

Kim, K. A., \& Nofsinger, J. R. (2008). Behavioral finance in Asia. Pacific-Basin Finance Journal, 16, 1-7.

Koirala, P., \& Bajracharya, P. (2004). Nepalese capital market: Issues and challenges. Economic Review, 16(1), 62-79.

Kumar, S., \& Goyal, N. (2015). Behavioural biases in investment decision making - A systematic literature review. Qualitative Research in Financial Markets, 7(1), 88-108.

Kumar, S., \& Goyal, N. (2018). Exploring behavioral biases among Indian investors: A qualitative inquiry. IMI Konnect, 7(1), 51-68.

Kyle, A. S. (1985). Continuous auctions and insider trading. Econometrica: Journal of the Econometric Society, 53(6), 1315-1335.

Ranjbar, M. H., Abedini, B., \& Jamali, M. (2014). Analyzing the effective behavioral factors on the investor's performance in tehran stock exchange. International Journal of Art \& Humanity Science, 1(2), 80-86.

Shabgou, M., \& Mousavi, A. (2016). Behavioral finance: Behavioral factors influencing investors' decisions making. Advanced Social Humanities and Management, 3(1), 1-6.

Slovic, P. (1972). Psychological study of human judgement: Implications for investment decision making. Journal of Finance, 27, 779-801.

Shah, A. K., \& Oppenheimer, D. M. (2008). Heuristics made easy: An effort-reduction framework. Psychological Bulletin, 134(2), 207-222.

Shefrin, H. (2005). A Behavioral Approach to Asset Pricing. Elsevier.

Shleifer, A. (2000). Inefficient markets: An introduction to behavioural finance. Oxford University Press Inc.

Simon, H.A. A (1955). Behavioural model of rational choice. The Quarterly Journal of Economics, 69(1), 99-118.

Statman, M. (2008). What Is Behavioral Finance (Vol. 2). John Wiley \& Sons, Inc.

Statman, M., Fisher, K. L., \& Anginer, D. (2008). Affect in a behavioral asset pricing model. Financial Analysts Journal, 64(2), 20-29.

Tachiwou, A. M. ( 2010). Stock market development and economic growth: The case of West African Monetary Union. International Journal of Economics and Finance, 2(3), 127-142.

Tversky, A., \& Kahneman, D. (1981). The framing of decisions and the psychology of choice. Science, 211(4481), 453-458. 
Waweru, N. M., Munyoki, E., \& Uliana, E. (2008). The effects of behavioural factors in investment decision-making: a survey of institutional investors operating at the Nairobi Stock Exchange. International Journal of Business and Emerging Markets, 1(1), 24-41.

Yalcin, K. C., Tatoglu, E., \& Zaim, S. (2016). Developing an instrument for measuring the effects of heuristics on investment decisions. Kybernetes, 45(7), 1052-1071.

Zahera, S. A., \& Bansal, R. (2018). Do investors exhibit behavioral biases in investment decision making? A systematic review. Qualitative Research in Financial Markets, 10(2), 210-251.

\section{Annex I \\ Operationalization of Study Variables}

\section{A) Investor Behavior}

\section{Heuristics}

The construct heuristic is measured through observed variables like overconfidence, gambler's fallacy, anchoring, availability, and representativeness. These observed variables are evaluated by using following statement in the survey questionnaire.

\section{Overconfidence}

I believe that my skills and knowledge of stock market can help to outperform the market.

\section{Gambler's fallacy}

I am normally able to anticipate the end of good or poor market returns at NEPSE.

\section{Anchoring}

i. I forecast the changes in stock prices in the future based on the recent stock prices

ii. I rely on your previous experience in the market for your next investment.

\section{Availability}

I consider the information from your friends and relatives as the reliable reference for your investment decisions.

\section{Representativeness}

i. I buy hot stocks and avoid stocks that have performed poorly in the recent past.

ii. I use trend analysis of some representative stocks to make investment decision for all stocks that you invest.

\section{Prospect}

Prospect behavior has been assessed by using variable like loss aversion, regret aversion and mental accounting. The following statements are used to take the opinion of the respondents regarding these variables.

\section{Loss aversion}

i. After a prior loss, I become more risk averse.

ii. After a prior gain I become more risk seeker than usual. 


\section{Regret aversion}

i. I avoid selling shares that have decreased in value and readily sell shares that have increased in value.

ii. I feel more sorrow about holding losers too long than about selling winning stocks too soon.

\section{Mental accounting}

I tend to treat each element of my investment portfolio separately.

\section{Herd}

Herd behavior has been examined by using the following statement in the survey questionnaire.

i. I usually react quickly to the changes of other investors' decisions and follow their reactions to the stock market.

ii. I often consider the information that majority of investors focus on when trading on the stock market.

iii. I often imitate decision of others when making own investment decisions.

iv. Bearish trend in the stock market forces me to follow group behavior regarding investment.

v. Bullish trend in the stock market forces me to follow group behavior regarding investment.

vi. Changes in Political decisions force me to follow herd behavior.

vii. Rumors in the market affect my own investment decisions making power.

viii. I often imitate decision of others when making own investment decisions.

\section{Market}

Market behavior has been tested by using the following statement in the survey questionnaire.

i. I consider carefully the price changes of stocks that I intend to invest in.

ii. Market information is important for my stock investment.

iii. I put the past trends of stocks under my consideration for my investment.

iv. I have the overreaction to price changes of stocks.

v. I analyze the company's customer preference before I invest in their stock.

vi. I study the market fundamentals of the underlying stock.

\section{B) Investment Performance}

Investment performance has been tested by using the following statement in the survey questionnaire.

i. The return rate of your recent stock investment meets your expectation.

ii. Your rate of return is equal to or higher than the average return rate of the market.

You feel satisfied with your investment decisions in the last year (including selling, buying, choosing stocks, and deciding the stock volumes). 